\title{
From school classes to UNESCO: IYL-enabled environments for tackling the STEM skills shortage through student-led outreach
}

Matthew Posner, Pearl John, Nicholas H. Wong, Vinita Mittal, Martin Nunez-Velazquez

Matthew T. Posner, Pearl V. John, Nicholas H. L. Wong, Vinita Mittal, Martin M. Nunez-Velazquez, "From school classes to UNESCO: IYL-enabled environments for tackling the STEM skills shortage through student-led outreach," Proc. SPIE 9946, Optics Education and Outreach IV, 994607 (27 September 2016); doi: 10.1117/12.2238222

EviE Event: SPIE Optical Engineering + Applications, 2016, San Diego, California, United States 


\title{
From school classes to UNESCO: IYL-enabled environments for tackling the STEM skills shortage through student-led outreach
}

\author{
Matthew T. Posner*a, Pearl V. John ${ }^{\text {a }}$, Nicholas H. L. Wong ${ }^{\text {a }}$, Vinita Mittal ${ }^{\text {a }}$, Martin M. Nunez- \\ Velazquez $^{\mathrm{a}}$ \\ ${ }^{a}$ University of Southampton, University Road, Southampton, SO17 1BJ, United Kingdom
}

\begin{abstract}
The accepted industrial skills shortage in the subjects of science, technology, engineering and mathematics (STEM) in the United Kingdom has led to an increasing drive for universities to work with a wider pool of potential students. One contributor to this drive is the Lightwave Roadshow, a photonics-focused outreach program run by postgraduate students from the University of Southampton. The program has benefitted from the unique platform of the International Year of Light (IYL) 2015 for the development and support of hands-on and interactive outreach activities. In this report we review Lightwave activities facilitated by IYL that focused on widening participation for students aged 6 to 18 years from a multitude of societal categories; the roadshow has directly benefitted from the significance and investment into the IYL in conjunction with university recruitment strategies, local schools and the support of international organizations such as SPIE and OSA. Lightwave has used the foundation of the IYL to provide a wide range of activities for over 1,200 UK students in 53 different schools; the assessment tools used to measure learning outcomes, reach and impact are also discussed. The program's activities have been developed to make younger age groups the center of the outreach activity and create an environment which encourages youth pursuit of optics and science from a grassroots level upwards; to illustrate this we will outline a Lightwave project endorsed by the IYL steering committee to permit two $6^{\text {th }}$ form students to attend the IYL opening ceremony in Paris.
\end{abstract}

Keywords: Optics education, Photonics outreach, Evaluation tools, Student chapter, Student-led outreach, Gender diversity in STEM, Widening participation, IYL 2015.

\section{INTRODUCTION}

The University of Southampton works with local schools, colleges, teachers, businesses, policy makers and the general public to engage them with our research for a number of reasons. These include promoting courses to potential students, teachers, parents and funders; as well as attempting to combat, in the long-term, the skills shortage in the photonics industry, and the lack of diversity (gender and other forms) in photonics. There are many other reasons to engage different publics with research and this paper explores some of them within the context of a set of student-led projects undertaken in collaboration with the Thomas Hardye School, Dorchester, UK. The projects centered around the 2015 International Year of Light (IYL 2015) celebrations, and in particular an outreach and public engagement activity which involved two 6th Form students attending the IYL 2015 opening ceremony at UNESCO headquarters in Paris, France.

This paper outlines models of activities that have benefitted from IYL 2015 and been made possible by a strong schooluniversity partnership. In Section 2, we set the context for these activities and introduce the key organizations involved. Section 3 describes types of activities that can be run as part of school-university partnerships, and we provide a case study of a class-based workshop. Section 4 provides an in-depth case study of the student-led delegation that attended the IYL 2015 opening ceremony; we outline the engagement of pupils before, during and after the ceremony and the impact that it had on participants and organizers. The paper concludes in Sections 5 and 6 by reflecting on the challenges and considerations in organizing these events.

*mp1g09@soton.ac.uk; phone +44 238059 2959; orc.soton.ac.uk 


\section{BACKGROUND}

In this section, we set the context of the activity that is described in this paper and the main partners in this project. We discuss the importance of having strong school-university partnerships to ensure greater impact than single, or one-off, events.

\subsection{The International Year of Light and Light-based Technologies}

On 20 December 2013, the UN General Assembly 68th Session proclaimed 2015 as the International Year of Light and Light-based Technologies (IYL 2015) ${ }^{1}$ to raise global awareness about how light-based technologies promote sustainable development and provide solutions to global challenges in energy, education, agriculture and health. A rich and dynamic environment was created to allow people at all levels to celebrate light. With education being a big part of the mission of IYL 2015, the authors have explored numerous ways of celebrating IYL 2015 with a wide range of activities putting postgraduate university students and school pupils at the center of the outreach activity.

\subsection{The Lightwave Roadshow}

The Lightwave Roadshow is an optics and photonics outreach program run by postgraduate research students (PGRs) through the University of Southampton's (UoS) Optics and Photonics Society (OPSoc). The program was established in 1998 by PGRs in the Optoelectronics Research Center (ORC) at UoS, and has seen many generations of students lead it. The authors listed have led and been part of the program in the 3 years running up to IYL 2015, during which time the program engaged with over 5,000 school pupils and members of the general public through school classes, and regional and national fairs. Through the outreach activities, the program's ambassadors develop their communication and presentation skills, and ability to work in various environments. From 2013 to 2015, 25 doctoral (PhD) students participated in the program, led by the then Lightwave Director, Posner. The Lightwave Director, in addition to acquiring ambassador skills, develops strong negotiation, budget, time and project management, and organization skills. The reader is referred to a recent paper describing the program dynamics and organization in detail ${ }^{2}$. Experience gained as students allows the program directors and experienced ambassadors to identify possible partnerships with external and internal partners in the university.

\subsection{The Thomas Hardye School}

The Thomas Hardye School (THS), Dorchester, UK, is an ages 13-18 mixed school rated as 'outstanding' by the UK's Office for Standards in Education, Children's Services and Skills (OFSTED) ${ }^{3}$. The school has a long-standing relationship with UoS through its Industrial Liaison Partner, Judith Wardlaw, and an established working relationship with co-author, John, Public Engagement Leader of UoS department of Physics and Astronomy (P\&A); all well documented in the school's STEM@THS annual newsletters ${ }^{4}$. THS is also a UNESCO associated school ${ }^{5}$. This, with the other strengths in the relationship, made it an ideal partner to work with for a number of different IYL-inspired events.

\subsection{Motivation for working within strong School-University Partnerships}

School-University Partnerships (SUPs) offer a rich and dynamic platform for delivering educational and impactful activities. Partnered institutions can obtain many mutual benefits including increasing pupil performance, understanding where research work fits into the curriculum, access to researchers of the future, sharing of best practices to improve pedagogy, training for school and university staff, and better collection of data for impact; the reader is referred to recent work by Wager describing comprehensively planning and delivery strategies for SUPs ${ }^{6}$. These benefits will impact the PGRs leading the activity and pupils at the center of it. The authors had extensive experience in taking part in the Lightwave program before IYL 2015, including work with the partner school, and were able to explore opportunities for collaborating with schools.

\section{IYL-DRIVEN ACTIVITIES THROUGH SCHOOL-BASED PARTNERSHIPS}

In this section, we offer the reader a selection of IYL-driven activities that have taken place through a strong SUP, and highlight the benefits to PGR student-leaders and school pupils. We provide a focused case-study on a class-based activity designed by PGRs for pupils of 12-14 years. 


\subsection{Formats of engagement}

A number of different activities were designed to enhance and diversify the SUP as part of the IYL 2015 celebrations, namely a poster competition, school assembly lectures, a research showcase, a hands-on class and the outreach activities at the IYL 2015 Opening Ceremony. We present the first three formats of engagements in this sub-section.

250 pupils carried out homework in which they were required to make an A3 poster to highlight one way in which lightbased technologies have changed lives. This gave the pupils an applied activity as homework for which prizes were available for the highly-commended posters. The introduction of a competition-based activity encouraged high-levels of time investment from the students in the pursuit of success; the winning poster on blue LEDs is presented in Figure 1 (a). The benefits of the competition included training the science teachers in photonics applications and raising awareness of current research at the grassroots level in schools. The PGRs gained skills in setting up a homework exercise, highlighting the relevance of current research to pupils' lives, and administering an adjudicating process to assess the students' posters as described in Video 1.

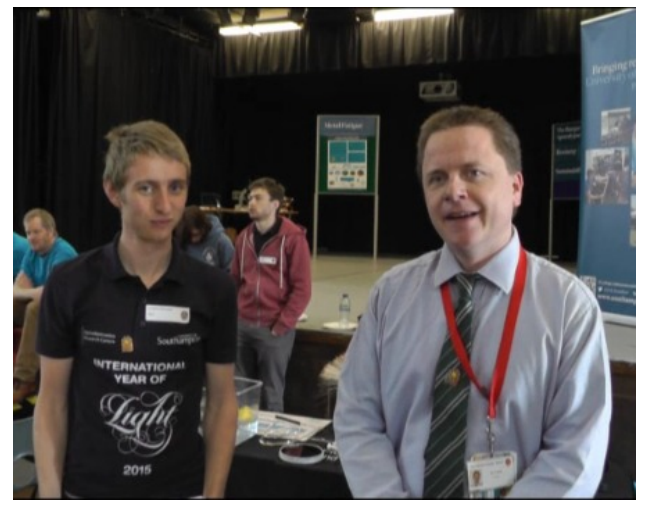

Video 1. A label of the description of the THS IYL 2015 poster competition. Posner designed the competition, adjudicated it and announced the winner. https://www.thomas-hardye.net/pages/news/2015/04-15/IYLPoster/IYLPoster.php.

The PGRs and a university academic gave a number of school assembly lectures; the delegation that attended THS during IYL 2015 is shown in Figure 1 (b) together with THS staff. The transport and logistics costs were covered by the ORC and P\&A departments, as these types of events are useful to report to funding agencies and for marketing and recruitment purposes. The primary aim was to broaden the perspective of pupils and to encourage consideration of a studentship or career in research. The PGRs gained experience in managing scheduled visits and communication between the school and academics. The sessions could have been complemented by careers information and personal accounts from the postgraduate students on their academic progression. Students acted as role models for the younger generation of school pupils in this manner. PGRs also gained from exposure to high-level research talks carried out by senior academic staff for their own public engagement and from engaging with large audiences. This valuable experience teaches PGRs communication skills when they reflect on what worked, and what did not work so well, for large and small audiences.

A Lightwave Roadshow workshop was developed to introduce Year 10 pupils (aged 14-15 years) to the concept of laser communications, describing total internal reflection, and to explain the optoelectronics research carried out at UoS. The workshop consists of a 10-minute overview with demonstrations that can be showcased repeatedly to multiple small audiences. This workshop was run for the first time during IYL 2015 and the Lightwave ambassadors (Figure 1 (c)) engaged with 400 students during a 4-hour period. The learning for the PGRs included developing the workshop, including activities, and producing suitable educational resources for students and promotional materials. Students developed communication skills, and teaching and learning skills such as how to appropriately answer pupils' questions in class. The pupils gained from being made aware of many different areas of research and the process of research. 


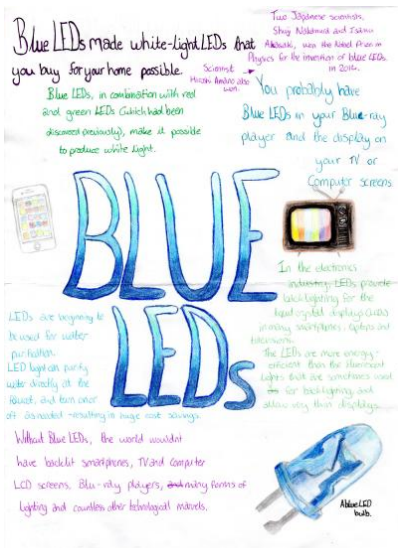

(a)

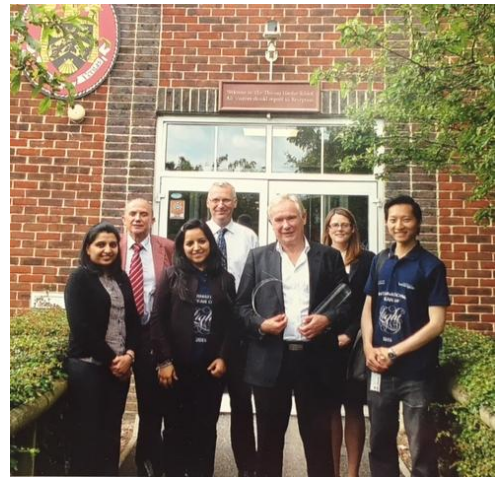

(b)

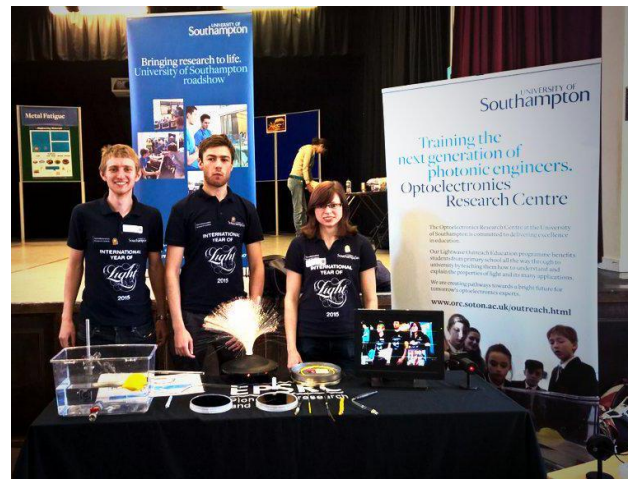

(c)

Figure 1. Examples of IYL-inspired activities carried out as part of an SUP between UoS and THS. (a) IYL 2015 poster competition winner, 'Blue LEDs' by Abi Davis, Year 9. (b) 'From Glass to Google', school lecture by Prof. Sir David Payne with supporting student delegation. (c) Lightwave ambassadors presenting their research in optoelectronics in a 10minute workshop at the 2015 THS 'Bringing Science to Life' Roadshow.

IYL 2015 fostered the development of many new activities to enrich the SUP. The benefits were universally recognized, from the pupils to the professors who presented. The PGRs had to work to maintain good communication with multiple parties to ensure the thorough organization and unified logistics. It proved to be a steep-learning curve, particularly with the formalities of documentation and risk assessments; support was gratefully received from experienced outreach and teaching staff who facilitated the learning process. Planning was key before beginning the project.

Through the activities described above, we engaged with 1,125 students between UK Year 8 and Year 10 aged 12-15 years old from THS alone. Measuring the significance of the impact of this interaction for the pupils was challenging. We present as an example a class-based activity to obtain more comprehensive forms our evaluating our impact.

\section{2 "Communicating with Light": class-based student-led outreach}

In the following section we provide details of an outreach activity for school pupils designed by PGR students. A workshop called "Communicating with Light" was developed for pupils and delivered at THS to mark the start of the IYL 2015 celebrations (the workshop was developed independently of the highly-acclaimed presentation for adults presented by Prof. P. Bayvel at the Royal Society in $2014^{7}$ ). The preparation of the school workshop required PGRs to research the relevant areas of the national curriculum ${ }^{8}$, to understand where their research work fitted into the school curriculum.

The workshop was developed, with the support of an SPIE IYL 2015 outreach education grant ${ }^{9}$, to present the underlying laser science and fibers optics technologies used for the development of the Internet. The class-based engagement combines an introduction to algorithms for coding signals (Morse code), and demonstrations of laser communication and total internal reflection. Alongside the technical elements, it presents an insight into PGRs' research to show what the work of a scientist entails. The class aims to raise aspirations and broaden the horizon of pupils to include the consideration of research and science based careers. The learning outcomes for the pupils were that they were able to explain the relevance of elements of their syllabus to research applications.

The workshop's success was evaluated through questionnaires which the pupils completed. The questionnaires included elements to assess the pupils' learning, their enjoyment of the workshop and to evaluate the impact of the activity. The class generally received very positive feedback. One challenge is that the PGRs leading the class do not have exact prior knowledge of the pupils' progress in the national curriculum. Further considerations include obtaining feedback from the teachers, who only act in a supporting role during the class, yet could provide insightful knowledge into the pupils' degree of interaction and the class' relevance to the national curriculum.

The Lightwave Director developed valuable skills through the class design, preparation, delivery and evaluation of the workshop. Associated Lightwave ambassadors developed valuable communication \& presentation skills, and in addition, 
presented their research in an accessible way to pupils. Public engagement officers can provide feedback for PGRs running the class.

\section{THE INTERNATIONAL YEAR OF LIGHT OPENING CEREMONY: A CASE STUDY OF STUDENT- LED OUTREACH}

We review in detail a case-study of a graduate student-led project with high impact on the students, school pupils and staff involved.

\subsection{Project aim and objectives}

IYL 2015 offered a number of special opportunities for activities. The lead author designed an outreach activity to allow two local pupils, four PGR students and accompanying support teachers and staff from THS and UoS, respectively, to participate in the opening ceremony at the UNESCO headquarters in Paris, France.

The project was designed to ensure that the students participated in a meaningful, impactful way. Several objectives were identified:

1. To showcase the outreach activities conducted by our Lightwave program, including the feature of hands-on experiments on a number of optics topics. This will raise the international profile of Lightwave.

2. To be an opportunity for students, especially the school pupils, to gain exposure and professional development experience by attending a prestigious event involving delegates from all sectors of the international optics and photonics community.

3. To sustain the visibility of our outreach beyond the opening ceremony, via publicity mechanisms such as recorded interviews with the student participants, reflective articles, press releases and promotion to THS' sister schools.

The project relied on UoS becoming a gold sponsor of IYL 2015 for a number of reasons. Firstly, this secured exhibition space for our outreach as well as delegate tickets. Secondly, the gold status guaranteed global exposure through a continuous presence on the IYL website and other media. We sought departmental and faculty support to realize this.

\subsection{Student-led outreach}

All members from the PGR Outreach and PER team were selected based on previous commitment to our Lightwave Roadshow and had extensive experience on activities in schools and science fairs aimed at members of the general public, including the design, delivery and evaluation of the engagement activities. A considerable amount of preparation was required to orchestrate this project. The students designed the project proposal and secured funding from the ORC and UoS Faculty of Physical Sciences and Engineering for the project take place. In addition, they organized travel and lodging arrangements for the delegation, equipment transportation, and preparation of relevant documentation (risk assessments, letters to parents of the pupils, the travel itinerary, emergency contact details, etc.). The exercise presented a steep learning curve for all PGRs involved, and the process was facilitated by experienced university staff; the reader is referred to a recent report for a review of challenges and considerations of doing international outreach ${ }^{10}$.

The lead author also managed communication with THS to select the pupils that would attend the delegation. The initial contact was facilitated through a strong SUP, and a common desire to be part of a 'once in a lifetime' event. 7 students from THS were shortlisted by their teachers to put forward nominations to take part in the delegation. The students were asked to write two 200-word essays: 1) a short 'research' essay on "What is the International Year of Light?" and 2) a personal statement on "Why should I be selected to be part of the delegation?" The applications were accompanied by the students' achieved and predicted exam grades and their intended higher education course of study after leaving school. The submissions were reviewed by the lead author and individual feedback was offered to each candidate. Eventually, THS students Katharine Bennett and Raphael Treccani-Chinelli were selected to form part of the delegation; see Figure 2 (a). A physics teacher, Geoffrey Reader, was selected by the school to join the delegation in a supporting role.

The two THS pupils were given an OSA Optics Discover kit ${ }^{11}$. They were asked to explore the kit, familiarize themselves with it, and bring it to Paris, with the intention to be able to comfortably showcase the experiments to exhibition attendees, who included policy makers, educators, artists and researchers. 
The activities at the opening ceremony included staffing our outreach stand at the event. Our delegates talked to exhibition attendees about the outreach exhibits on the stand, thereby improving their communication and presentation skills. The conference featured a number of talks from a range of distinguished speakers, including Nobel laureates, world-leading scientists, artists, etc.; see Figure 2 (b) for a group picture in the exhibition center. The delegates also had the chance to network during social events and meet senior academic staff from the ORC; see Figure 2 (c).

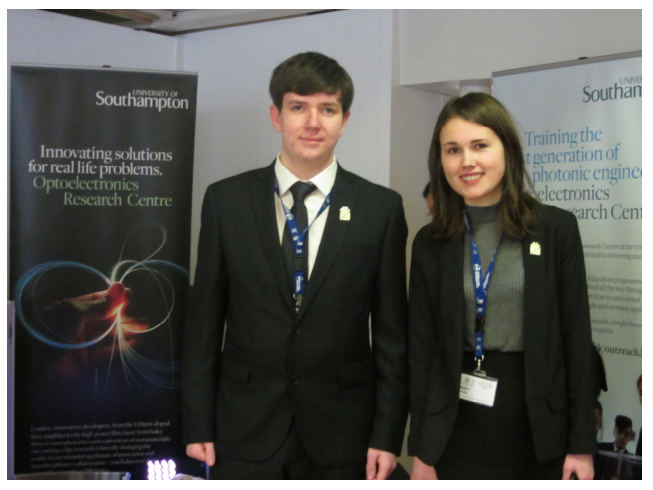

(a)

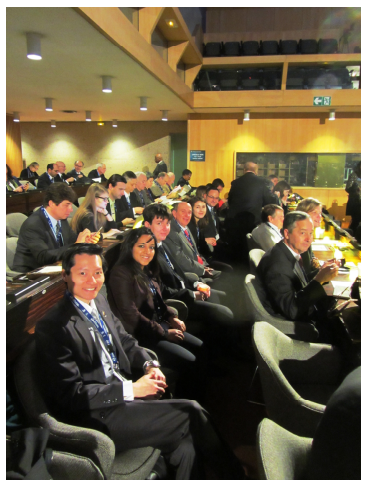

(b)

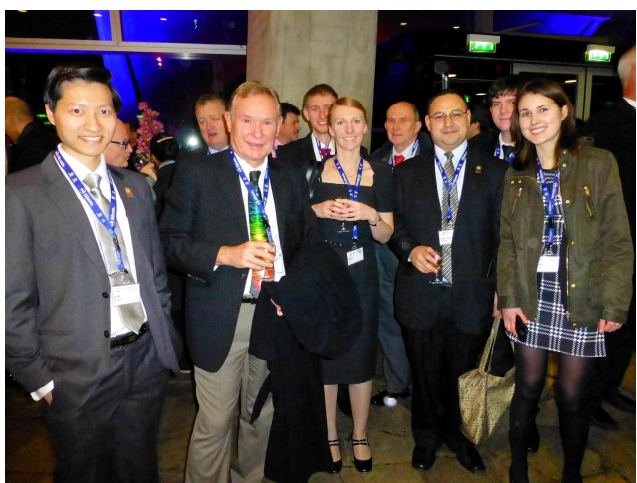

(c)

Figure 2. UoS students and THS pupils at the IYL 2015 opening ceremony. (a) THS pupils Katharine Bennett and Raphael Treccani-Chinelli by the UoS exhibition booth. (b) Student delegation in the UNESCO conference center. (c) Graduate students and pupils network with ORC senior staff at the IYL 2015 drinks reception.

\subsection{Impact}

The project was documented in a variety of formats, including personal blogs ${ }^{12}$, press $^{13,14}$, school newsletters ${ }^{15}$, and institutional news articles ${ }^{16}$. With the assistance of the UoS Institute for Learning Innovation and Development ${ }^{17}$, the students produced a video report to relate their experiences of the IYL 2015 opening ceremony; see Video 2.

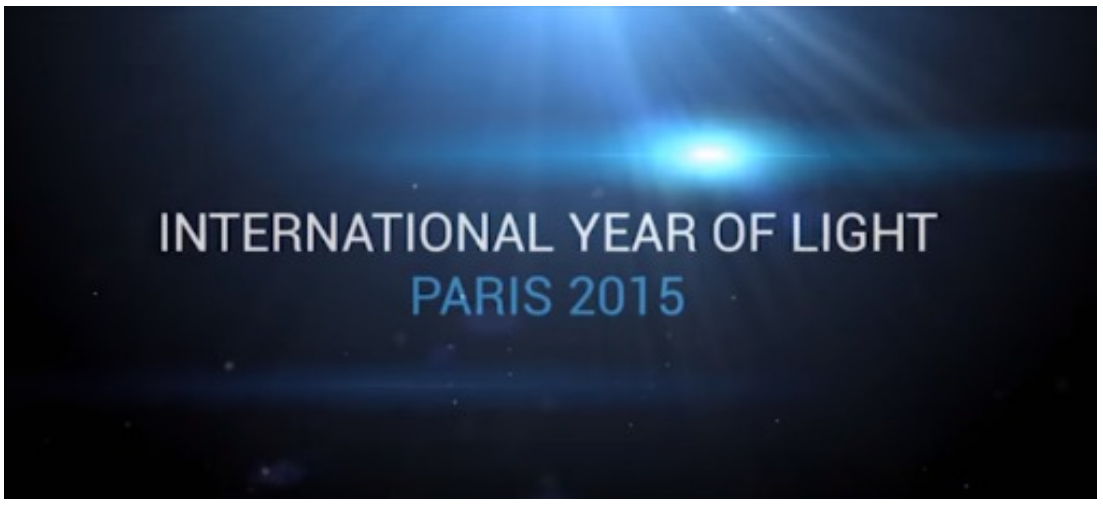

Video 2. A label of "Year of Light", a video report from members of the IYL 2015 UoS student-led delegation about their experiences of the IYL 2015 opening ceremony. https://www.youtube.com/watch?v=sDMa4pWdYc4.

The most significant impact was felt by the members of the delegation, and we illustrate this in Table 1 with a selection of quotes from the delegates collected during and shortly after the IYL 2015 opening ceremony. The ceremony left a strong impression by its richness, scale and diversity, all of which surpassed the expectations of the delegates (Table 1, \#1-3). Individuals were struck by inspiring stories and accounts of where light had been used to solve real-world problems (Table 1, \#4,5). The impact on the delegates is felt in quotes \#6-10, and the feelings caused by this endeavor may have led to a number of positive outcomes. 
Table 1. Selected quotes from members of the delegation after the IYL 2015 opening ceremony.

\begin{tabular}{|c|c|c|}
\hline \# & Quotes & \\
\hline 1 & $\begin{array}{l}\text { "We have been given the chance to attend an international event that is also attended by } \\
\text { delegates from all over the world; policy makers, scientists, and Nobel laureates." }\end{array}$ & PGR student \\
\hline 2 & $\begin{array}{l}\text { "[The opening ceremony] shows different people from different areas, different } \\
\text { countries, different cultures are all working within this same area of light." }\end{array}$ & PGR student \\
\hline 3 & $\begin{array}{l}\text { "The scale of the opening ceremony made it so special. There were so many people there } \\
\text { that you were just completely engrossed in the science." }\end{array}$ & THS pupil \\
\hline 4 & $\begin{array}{l}\text { "I will never forget the story by the laser surgeon working in Vietnam who explained } \\
\text { how she and her team performed free surgery on girls with birthmarks. Having a } \\
\text { birthmark for most Vietnamese women would preclude them from working or marrying } \\
\text { for cultural reasons. The simple laser surgery removing the birthmarks transformed the } \\
\text { girls' lives. What a fantastic transformative application of laser technology. I tell } \\
\text { everyone about that story when I'm giving talks." }\end{array}$ & PE leader \\
\hline 5 & $\begin{array}{l}\text { "A lot of people think that science and art are two separate things and actually you need } \\
\text { both of them and you need them to work together." }\end{array}$ & THS pupil \\
\hline 6 & "We feel we have sat amongst giants of science." & THS teacher \\
\hline 7 & "It's reminded me why I love physics so much." & PGR student \\
\hline 8 & $\begin{array}{l}\text { "I'm extremely grateful to the Outreach Director that I had the opportunity to attend the } \\
\text { Ceremony." }\end{array}$ & PE leader \\
\hline 9 & "It's reassuring to me that I am doing something that is going to benefit mankind." & PGR student \\
\hline 10 & $\begin{array}{l}\text { "Now it is our responsibility to pass the baton; to take the responsibility and educate at } \\
\text { the very basic level to teach them about photonics and light and how light has made a } \\
\text { difference in our lives." }\end{array}$ & PGR student \\
\hline
\end{tabular}

There were a number of positive outcomes as a result of this project. Firstly, it generated renewed student interest in photonics, exemplified by a visit from THS pupil Raphael Treccani-Chinelli to the ORC and UoS nanofabrication cleanrooms.

Secondly, the outreach activity led us to develop a portable set of experiments to take to international conferences and schools overseas; see Figure 3 (a) where the "Outreach Handbag" was demonstrated at the 2015 SPIE Optics + Photonics Outreach Games. The kit, which more recently was named the "Compact Optics Suite", has been used by us in many events abroad and also won the 2015 OSA "IYL-To-Go" student chapter competition, as detailed in 10.

Thirdly, we gained confidence to work with non-traditional audiences. This enabled us to subsequently carry out a project involving a photonics-themed garden that allowed us to reach members of the public who would not normally have contact with optics and photonics ${ }^{18}$. In addition, we adapted our pedagogy methods to engage with adults with learning difficulties ${ }^{19}$.

Fourthly, the professional networks established resulted in numerous researcher development opportunities for the PGRs involved, such as invitations to international trade fairs and congresses; invited talks at the British science festival (see Figure 3 (b)), the Royal society public engagement symposium and the regional Salisbury Café Scientifique ${ }^{20}$; and chances to submit academic papers and present our work at international conferences such as this.

Finally, our status as a gold sponsor of IYL 2015 has enhanced the international visibility of UoS and the Lightwave program in particular. 


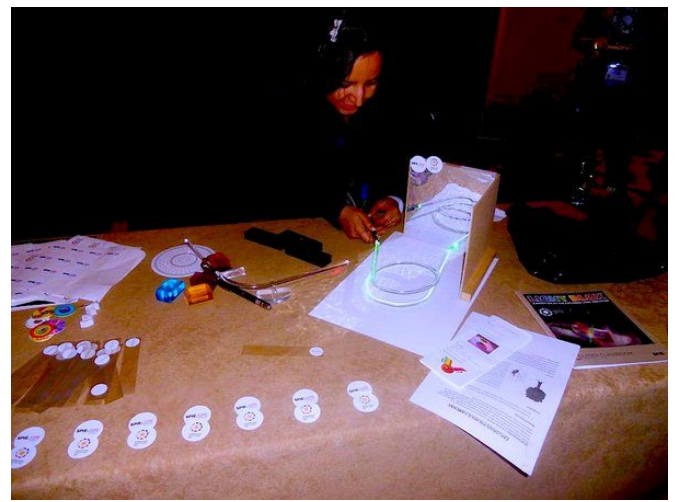

(a)

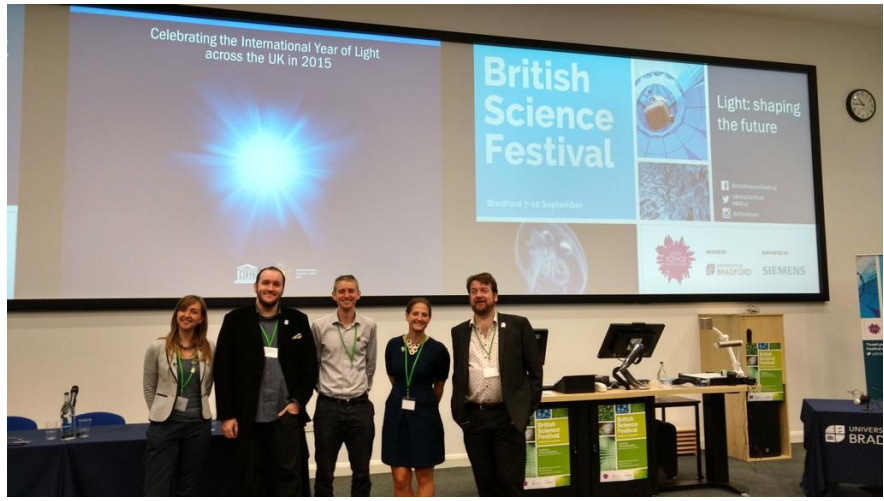

(b)

Figure 3. (a) Mittal represented the Lightwave Roadshow at the 2015 SPIE Optics + Photonics Optics Outreach Games (b) Posner was invited to present a talk at the British Science Festival's IYL 2015 panel "Light: shaping the future".

\section{LESSONS LEARNED}

Our experiences have highlighted the need for thorough planning before going into schools to mitigate challenges and risks associated with working in schools. It is helpful to identify key players in SUPs, such as industrial liaison partners in schools or outreach and public engagement officers at universities, and utilize their experience in developing and delivering class-based activities. Assessment methods must be planned in advance to efficiently assess pupils, and setting achievable goals is important for school projects; for example, having the aim of 'expanding pupils' horizons' is a difficult goal at pre- and post-test stages in order to prove that the workshops' objectives have been met. Measuring the long-term impact of a project is challenging: unless one can have contact details for students over the long-term, and the project has funding to track the progression of the students, it is difficult to demonstrate a correlation between present activities and admissions into physics or electronics engineering undergraduate courses, for instance. We note that strong SUPs can help monitor pupil progress throughout their formative school years.

The experiences of student-led outreach are of considerable benefit to PGRs leading and taking part in the activity. They provide stimulating student experiences beyond the laboratory and pure academia, and can offer advice on routes to develop important employability skills. The Lightwave program would benefit from more rigorous methods of selfassessment for PGRs leading student activities, and will endeavor to explore, with experienced outreach and public engagement officers, what best strategies could be used to implement this.

\section{CONCLUSIONS}

We have presented formats of events that can be used in the context of a SUP, and presented case studies of student-led outreach activities with significant impact for the activity leaders. SUPs create a dynamic environment for outreach and public engagement activities. Outreach roles play an important part in the development of employability skills for students, in particular for organizers of the activity. We have identified some of the challenges in preparing these events, and we have found that it is worth investing in PGR student training and providing them with the opportunities to learn valuable skills of negotiation, project management, time management, organization and budget management. Suitable staff experience must be in place to facilitate this process. Of note is that experienced students and partners can explore novel opportunities in high impact events, and mutually benefit from these projects. We have found that the biggest impact is on the students and pupils at the center of the activity, and it will influence the directions they take in their future career.

\section{ACKNOWLEDGEMENTS}

The authors acknowledge support from the Optoelectronics Research Centre and the Faculty of Physical Sciences and Engineering for funding the student delegation travel costs to the opening ceremony and sponsoring the IYL 2015 steering committee; the OSA \& SPIE for funding outreach kits through the 2015 International Year of Light student 
chapter outreach activity grants; the EPSRC-funded Centre for Innovative Manufacturing in Photonics (grant $\mathrm{EP} / \mathrm{H} 02607 \mathrm{X} / 1$ ) for funding postgraduate researchers to run the Lightwave Roadshow for activities carried out during IYL 2015; Mrs. Judith Wardlaw from the Thomas Hardye School for her initiative, drive and enthusiasm and key role in this collaboration; and all of the Lightwave ambassadors who have contributed to the running of the Lightwave Roadshow during IYL 2015.

\section{REFERENCES}

[1] UN General Assembly, Resolution 68/221, "International Year of Light and Light-based Technologies, 2015.”, A/RES/68/221 (2014).

[2] Wong, N. H. L., Posner, M. T.., John, P. V., "The Lightwave Programme and Roadshow: An Overview and Update," Proc. SPIE 9793, 97932 V (2015).

[3] OFSTED., "The Thomas Hardye School," 2016, <http://reports.ofsted.gov.uk/inspection-reports/find-inspectionreport/provider/ELS/137163> (7 August 2016 ).

[4] Wardlaw, J., "STEM Newsletters," <http://www.thomas-hardye.net/pages/information/STEM.php> (7 August 2016 ).

[5] UNESCO., "UNESCO Associated Schools Programme (ASPNet)," 2016, $<$ http://www.unesco.org.uk/designation/unesco-schools/> (7 August 2016).

[6] Wager, L., Building School-University Parternships Guide Book, 1st ed., J. Spurrell, Ed., University of Southampton, Southampton (2016).

[7] Bayvel, P., “Communicating with Light," 2014, <https://royalsociety.org/events/2014/10/clifford-paterson/> (5 May 2015 ).

[8] DoE., "National curriculum in England. Science programmes of study: key stage 3," 2013, $<$ https://www.gov.uk/government/uploads/system/uploads/attachment_data/file/335174/SECONDARY_national _curriculum_-_Science_220714.pdf> (8 August 2016 ).

[9] Standen, D., "Lightwave receives SPIE Activity Award for International Year of Light," 2014, $<$ http://www.orc.soton.ac.uk/884.html> (7 August 2016 ).

[10] Wong, N. H. L., Posner, M. T., Mittal, V., Gray, D. R.., John, P. V., "Taking local optics outreach abroad for IYL 2015: administrative and logistical challenges and strategies," Proc. SPIE 9946, 9946-14 (2016).

[11] “Optics Discovery Kit.", <http://www.edmundoptics.com/optics/optical-lenses/lens-kits/optics-discoverykit/1865/> (5 May 2015 ).

[12] Wong, N. H. L., "Light is Now: the International Year of Light Opening Ceremony," $<$ https://spectroverse.wordpress.com/2015/01/31/light-is-now-the-international-year-of-light-openingceremony/> (9 June 2015 ).

[13] Hogger, H., "Bright sparks from Thomas Hardye School travel to Paris for launch of international event," 2015, $<\mathrm{http} / /$ www.dorsetecho.co.uk/news/localnews/dorchester/11733560.Bright_sparks_travel_to_Paris_for_launch_ of_international_event/> (8 August 2016 ).

[14] "International Year of Light Delegation.", $<\mathrm{http}$ //www.dailyecho.co.uk/news/11733717.International_Year_of_Light_delegation/> (7 June 2015 ).

[15] Wardlaw, J., “STEM@THS,” 12, 2015, <https://www.thomas-hardye.net/documents/ScienceCollegeNews2015 Final.pdf> (7 August 2016 ).

[16] Standen, D., "Students attend global launch of the International Year of Light," 2015, $<$ http://www.orc.soton.ac.uk/iylopens.html> (8 August 2016 ).

[17] ILIAD., "Institute for Learning Innovation and Development," $<$ http://www.southampton.ac.uk/iliad/index.page> (8 August 2016 ).

[18] Posner, M. T., John, P. V., Standen, D., Wheeler, N. V., van Putten, L. D., Soper, N., Parsonage, T., 
Wong, N. H. L.., Brambilla, G., "Reflecting photonics: Reaching new audiences through new partnerships: IYL 2015 and the Royal Horticultural Society flower show," Proc. SPIE 9946, 9946-2 (2016).

[19] Posner, M. T., van Putten, L. D.., Bellworthy, R. M., "Mencap-Lightwave: Outreach with Young Adults with Learning Disabilities," 2016, <http://www.osa.org/en-us/the_optical_society_blog/2016/june/mencaplightwave_outreach_with_young_adults_with/> (8 August 2016 ).

[20] "Salisbury Café Scientifique 'From heliographs to the Internet: celebrating Light.", 2015, $<$ http://cafescientifiquesalisbury.org.uk/2015/09/light/> (8 August 2016) 